OPEN ACCESS

Edited by:

Luigi Iuliano,

Sapienza University of Rome, Italy

Reviewed by:

Ezzedine Aouani,

University of Carthage, Tunisia

David Bernlohr,

University of Minnesota Twin Cities,

United States

*Correspondence:

Patricia Fiorino

patriciafiorino@mackenzie.br

tThese authors have contributed equally to this work

Specialty section:

This article was submitted to Lipid and Fatty Acid Research,

a section of the journal

Frontiers in Nutrition

Received: 22 December 2018 Accepted: 15 April 2019

Published: 03 May 2019

Citation:

Muller CR, Leite APO, Yokota $R$

Pereira RO, Americo ALV, Nascimento NRF, Evangelista FS, Farah V, Fonteles MC and Fiorino $P$ (2019) Post-weaning Exposure to High-Fat Diet Induces Kidney Lipid Accumulation and Function Impairment in Adult Rats. Front. Nutr. 6:60

doi: 10.3389/fnut.2019.00060

\title{
Post-weaning Exposure to High-Fat Diet Induces Kidney Lipid Accumulation and Function Impairment in Adult Rats
}

\begin{abstract}
Cynthia R. Muller ${ }^{1,2}$, Ana Paula O. Leite ${ }^{1,3}$, Rodrigo Yokota $^{3}$, Renata O. Pereira ${ }^{1,4}$, Anna Laura V. Americo ${ }^{1,2}$, Nilberto R. F. Nascimento ${ }^{5}$, Fabiana S. Evangelista ${ }^{6}$, Vera Farah ${ }^{1,4}$, Manasses C. Fonteles ${ }^{1,5 t}$ and Patricia Fiorino ${ }^{1 * t}$
\end{abstract}

\footnotetext{
${ }^{1}$ Renal, Cardiovascular and Metabolic Physiopharmacology Laboratory, Health and Biological Science Center, Mackenzie Presbyterian University, São Paulo, Brazil, ${ }^{2}$ Experimental Pathophysiology Department, Faculty of Medicine, University of São Paulo, São Paulo, Brazil, ${ }^{3}$ Department of Medicine, Renal Division, Federal University of São Paulo, São Paulo, Brazil, ${ }^{4}$ Department of Medicine, Translational Medicine Division, Federal University of São Paulo, São Paulo, Brazil, ${ }^{5}$ Superior Institute of Biomedical Sciences, Ceara State University, Fortaleza, Brazil, ${ }^{6}$ School of Arts, Science and Humanities, University of Sao Paulo, São Paulo, Brazil
}

Aim: We investigated the kidney morphofunctional consequences of high-fat diet intake since post-weaning in adult rats.

Main Methods: Male Wistar rats were divided into two groups: ND (normal diet; $n=10$ ) and HD (high-fat diet; $n=10$ ). The high-fat diet was introduced post-weaned and animals were followed for 8 weeks.

Key Findings: HD group did not change body weight gain even though food consumption has decreased with no changes in caloric consumption. The HD group showed glucose intolerance and insulin resistance. The glomerular filtration rate (GFR) was decreased in vivo (ND: $2.8 \pm 1.01$; HD: $1.1 \pm 0.14 \mathrm{ml} / \mathrm{min}$ ) and in the isolated perfusion method (34\% of decrease). Renal histological analysis showed a retraction in glomeruli and an increase in kidney lipid deposition (ND: $1.5 \pm 0.17$ HD: $5.9 \pm 0.06 \%$ ). Furthermore, the high-fat diet consumption increased the pro-inflammatory cytokines IL-6 (ND: 1,276 \pm 203; HD: 1,982 \pm 47 pg/mL/mg) and IL-1b (ND: $97 \pm 12$ HD: $133 \pm$ $5 \mathrm{pg} / \mathrm{mL} / \mathrm{mg}$ ) without changing anti-inflammatory cytokine IL-10.

Significance: Our study provides evidence that high-fat diet consumption leads to renal lipid accumulation, increases inflammatory cytokines, induces glomeruli retraction, and renal dysfunction. These damages observed in the kidney could be associated with an increased risk to advanced CKD in adulthood suggesting that reduction of high-fat ingestion during an early period of life can prevent metabolic disturbances and renal lipotoxicity.

Keywords: post-weaning, high-fat diet, kidney lipid deposition, lipotoxicity, inflammation 


\section{INTRODUCTION}

High-fat diets are becoming increasingly common in many countries and they contribute to the development of chronic noncommunicable diseases (NCDs), such as obesity, hypertension, and chronic kidney disease (CKD) (1). NCDs kill 41 million people each year, $71 \%$ of the world's total deaths (2). It is recommended that fats account for $20-35 \%$ of total energy intake (3), but daily total fat consumption accounts for $50 \%$ of total energy intake in some countries (4).

High-fat diets, in general, are associated with metabolic disorders, and the type of dietary fat is a determinant risk factor since saturated fats are more linked to a positive fat balance and visceral adipose tissue accumulation than to other types of fat (5). Saturated fat intake is also more associated with increased serum LDL and total cholesterol than the consumption of other fatty acids (6). The World Health Organization recommends a reduction in saturated fat consumption as one of the worldwide strategies to reduce mortality from chronic NCDs (7).

Children are important targets for food and beverage companies that use aggressive advertising strategies to generate a preference for diets with high levels of fat. As a result, the consumption of high-fat diets typically starts early in life, especially in developed and developing countries (8). High-fat diet habits in childhood can predict the development of several diseases in adulthood, such as obesity, hypertension, metabolic syndrome, and $\operatorname{CKD}(9,10)$. Our group demonstrated that highfat diet ingestion since the early period of life increases white visceral adipose tissue and induces cardiometabolic damage in adult rats (11). Te Morenga et al. (12) showed that a reduction of saturated fat intake was associated with significant reductions in LDL and total cholesterol and arterial blood pressure of children and adolescents aged 2-19 years old (12).

High-fat diet affects the energy balance (13) leading to lipid accumulation in ectopic sites and in intracellular compartments $(14,15)$. The renal ectopic accumulation of lipids associated with insulin resistance has been correlated with a progressive decline in renal function $(14,16,17)$. The deleterious effects exerted by lipids on cells and tissues is called lipotoxicity $(18,19)$.

Many studies have demonstrated the link between altered lipid metabolism and the development of kidney injury in mice fed a high-fat diet $(14,17,20,21)$. The literature reports an important association between renal lipid accumulation and increased renal pro-inflammatory mediators, such as interleukin1 (IL-1), interleukin-6 (IL-6), and tumor necrosis factor alpha $(\mathrm{TNF} \alpha)$ (19). Furthermore, excessive renal lipid deposition can lead to renal tubular cell injury (22), tubulointerstitial fibrosis (23), podocytes damage, mesangial sclerosis (24), and structural glomeruli alterations $(25,26)$. Renal lipotoxicity is also strongly associated with the development of proteinuria, glomerulonephritis, and CKD (27). However, the role of renal lipid accumulation that could lead to kidney damage in a high-fat diet has not been completely understood.

Abbreviations: MCC, Mesangial cell contraction; HD, High-fat diet; ND, Standard normal diet.
Although the pathological consequences of a high-fat diet on the kidneys are well-documented, the repercussions in renal morphology and function as a result of a high-fat diet from an early age are not clear. Thus, the aim of this study was to investigate the effects of high-fat diet intake from weaning on the morphology and renal function of adult rats. We hypothesized that the intra-renal lipid accumulation induced by high-fat diet can be associated with damages in the renal morphology and function, leading to a higher risk of developing CKD in adulthood.

\section{MATERIALS AND METHODS}

\section{General Procedures}

Experiments were performed in male Wistar rats post-weaned (21 days old), weighing between 50 and $60 \mathrm{~g}$. The animals were randomly assigned to two groups and followed for 8 weeks: standard normal diet (ND, $n=10$ ) and high-fat diet (HD, $n=$ 10). The high-fat diet produced contained $30 \%$ of fat, $23 \%$ of carbohydrates and 19\% of proteins. The fat in HD is composed mainly of saturated fat. The standard diet contained $3 \%$ of fat, $55 \%$ of carbohydrate and $22 \%$ of proteins (Nuvilab ${ }^{\circledR}$, Paraná, Brazil). Caloric densities of a high-fat diet and standard diet were, respectively 381 and $257 \mathrm{kcal} / 100 \mathrm{~g}$. Animals were maintained in the Central Animal Facility at the Mackenzie Presbyterian University (Sao Paulo) under the same housing conditions (12$\mathrm{h}$ light/12-h dark cycle, temperature $23 \pm 2{ }^{\circ} \mathrm{C}$ ) with free access to tap water and food ad libitum. All procedures were performed in accordance with the Guide for the Care and Use of Laboratory Animals published by the US National Institutes of Health (n. 85-23, revised in 1996) and approved by the Ethics Committee of Mackenzie Presbyterian University (Protocol: 063/02/2010). Body weight was measured weekly at the same time of the day using a digital balance (TOLEDO, model 9094c/4). Body weight gain was calculated as the difference between the body weight measured at the beginning and at the end of the protocol.

\section{Glucose Tolerance Test (GTT)}

GTT was performed after 8-week protocol. After an 8$\mathrm{h}$ fast, glucose (1.5 g/kg body weight) was injected as a bolus intraperitoneally. Blood glucose concentration was determined by using a glucometer (AccuChek Advantage Roche Diagnostics $\left.{ }^{\circledR}\right)$. Blood samples were taken from a cut made on the tip of the tail at $0,15,30,60$, and $90 \mathrm{~min}$ after glucose administration. The area under the curve (AUC) was calculated using GraphPad Prism 5 (GraphPad Software Inc, San Diego, CA, EUA).

\section{Insulin Tolerance Test (ITT)}

Seventy two hours after the GTT test, a similar procedure was performed for ITT. Briefly, after a 4-h fast, rats were anesthetized with Pentobarbital (50 mg/kg body weight, i.p.) and an insulin load $(0.75 \mathrm{U} / \mathrm{kg}$ body weight) was injected as a bolus in the caudal vein. Blood glucose levels were determined from a cut made on the tip of the tail at $0,4,8,12$, and 16 min after insulin administration. Constant rate for blood glucose disappearance (Kitt) was calculated using the formula $0.693 / \mathrm{t} 1 / 2$, and the blood 
glucose half-time (t1/2) was calculated from the slope of the least squares regression of the blood glucose concentration during the linear phase of decline $(11,28)$.

\section{Kidney Function Evaluation}

In the 7th week of the protocol, the animals were housed individually in metabolic cages (Tecniplast, Buguggiate, VA, Italy). Urine samples were collected during the $24-\mathrm{h}$ period and used to determine urine creatinine. A blood sample $(500 \mu \mathrm{L})$ was also collected at the end of the $24 \mathrm{~h}$-period. Urinary and serum creatinine levels were quantified using a colorimetric method (LABTEST Biochemical Kit, Brazil). The creatinine clearance was used to estimate the Glomerular Filtration Rate (GFR) and was calculated using the following formula: [(Urine (Creatinine) $\times$ Urine Vol)/Serum (Creatinine)].

\section{Isolated Perfused Kidney Method}

At the end of the 8 weeks, rats were anesthetized with sodium pentobarbital $(50 \mathrm{mg} / \mathrm{kg}$ body weight i.p.) and the right renal artery was cannulated through the mesenteric artery, without blood flow interruption, and placed into the perfusion system (29), isolating the kidney from endocrine and neural interference. The perfusate was a modified Krebs-Henseleit solution with the following composition (in $\mathrm{mM}$ ): $147 \mathrm{Na}^{+}, 5 \mathrm{~K}^{+}, 2.5 \mathrm{Ca}^{2+}, 2.0$ $\mathrm{Mg}^{2+}, 110 \mathrm{Cl}^{-}, 25 \mathrm{HCO}^{3-}, 1 \mathrm{SO}^{2-}$, and $1 \mathrm{PO}^{3-}$. This was dialyzed for $48 \mathrm{~h}$ after the addition of six grams of bovine serum albumin (BSA) (29). Immediately before starting the perfusion, $100 \mathrm{mg}$ of glucose, $50 \mathrm{mg}$ of urea, and $50 \mathrm{mg}$ of inulin was added to the perfusate solution. The $\mathrm{pH}$ was then adjusted to 7.4 and the solution placed in the perfusion system. The perfused rat kidney model followed the technique previously described by Bowman and Maack and modified by Fonteles et al. $(29,30)$ by the introduction of a silastic membrane oxygenator into the perfusion line. Prior to each experiment, the system was calibrated for flow and resistance. Each experiment was divided into two periods of $30 \mathrm{~min}$ each, these sample collection periods were further subdivided into equal intervals of $10 \mathrm{~min}$. During each 10-min period, aliquots of perfusate and urine were collected to determine creatinine, sodium, and potassium. The perfusion pressure (PP), renal vascular resistance (RVR), urinary flow (UF), GFR, and the percentage of tubular transport of sodium $\left(\% \mathrm{TNa}^{+}\right)$, potassium $\left(\% \mathrm{TK}^{+}\right)$, and chloride $\left(\% \mathrm{TCl}^{-}\right)$ were determined. The percent of proximal and distal tubular sodium, potassium, and chloride transport were calculated using free water and osmolar clearances as described originally by Martinez-Maldonado and Opava Stitzer (31).

\section{Histological Analysis}

The left kidney was used for glomerular injury analysis in $\mathrm{H} \& \mathrm{E}$ stained (Sigma) sections of the kidney $(5 \mu \mathrm{m})$ embedded in Paraplast. Digital images from thirty glomeruli per animal were obtained using a light microscope (Leica) at 400x magnification. After digitalization, Bowman's capsule area (BCA), glomerular tuft area (GTA), and Bowman's space area (BSA) were traced and calculated using a computerized morphometric analysis system (Image Pro-Plus 4.1; Media Cybernetics, Silver Spring, MD, USA).
Lipid content was measured using quantitative histochemistry of Oil Red O (Sigma-Aldrich) stained kidneys. Tissue sections ( $8 \mu \mathrm{m}$ thickness) obtained in a cryostat were examined by light microscopy at 200x magnification and analyzed by a computerized morphometric analysis system (Image ProPlus 4.1; Media Cybernetics, Silver Spring, MD, USA). The slides were counterstained with hematoxylin to visualize the nuclei. Lipid accumulation was determined in 12 images per animal based on the percentage of area occupied by lipid droplets. Histological analyses were blinded conducted by RO Pereira.

\section{Cytokine Measurement}

In a subgroup of randomly selected rats (ND: $n=6$; HD: $n$ $=6$ ) cytokines were evaluated in the right kidney approved by the Ethics Committee of Mackenzie Presbyterian University (Protocol: 108/03/2014).

Measurement of cytokines was performed using the MILLIPLEX $^{\mathrm{TM}}$ cytokine panel (Merck Millipore, Billerica, MA), a bead-based immunoassay which allowed the simultaneous quantification of the cytokines IL-1b, IL-6, TNF- $\alpha$, and IL-10 in kidney samples. The results were normalized by kidney total protein.

\section{Statistical Analyses}

The statistical analysis was performed by using GraphPad Prism 5. The results were analyzed using the unpaired Student's $t$ test. The data were reported as mean \pm SEM. The $p$-value for significant differences was set at $p \leq 0.05$.

\section{RESULTS}

\section{Body Weight and Food Consumption}

No differences in body weight were observed between groups prior to or after the experimental protocol. In addition to this, no significant difference in body weight gain was found between groups. Although the food consumption (g/animal/24h) was reduced in the HD group, there was no difference in caloric intake (Kcal/animal/24-h) when compared to the ND group (Table 1).

TABLE 1 | Metabolic parameters at the end of the protocol of 8 weeks.

\begin{tabular}{lcc}
\hline & ND & HD \\
\hline Initial body weight (g) & $47 \pm 0.9$ & $49 \pm 0.8$ \\
Final body weight (g) & $312 \pm 7$ & $295 \pm 6.3$ \\
Weight gain (g) & $265 \pm 8$ & $246 \pm 6$ \\
Food consumption (g/animal/24h) & $26 \pm 0.3$ & $21 \pm 0.7^{*}$ \\
Caloric consumption (Kcal/animal/24h) & $79 \pm 1$ & $79 \pm 2.7$ \\
Fasting glucose (mg/dL) & $108 \pm 5$ & $99 \pm 6$ \\
AUC (mg/dL/min) & $144 \pm 6$ & $200 \pm 9^{\star}$ \\
Kitt (mg/dL) & $4 \pm 0.2$ & $3.3 \pm 0.2^{*}$
\end{tabular}

AUC, Area Under the Curve; Kitt, Rate constant for glucose disappearance; ND, Normal Diet; HD, High-Fat Diet. ${ }^{*} p \leq 0.05$ vs. ND. 


\section{Glucose Metabolism}

As shown in Table 1, high-fat diet consumption did not change fasting glucose but promoted an increase in the AUC and a decrease in Kitt.

\section{Renal Function}

Indices of kidney function are shown in Table 2 and Figure $\mathbf{1 .}$ There was a decrease in the in vivo GFR (ND: $1.8 \pm 0.19$; HD: 1.1 $\pm 0.14 \mathrm{ml} / \mathrm{min}$ ), UF (ND: $9.8 \pm 0.54 \mathrm{HD}: 3.7 \pm 0.19 \mathrm{~mL} / 24-\mathrm{h}$ ) and water intake (ND: $26.9 \pm 1.45$; HD: $16.75 \pm 1.35 \mathrm{~mL} / 24-\mathrm{h}$ ) in HD group when compared with ND. In addition, the serum creatinine was increased in HD (ND: $0.55 \pm 0.071$; HD: $0.71 \pm$ $0.14 \mathrm{mg} / \mathrm{dL}$ ).

In the isolated perfused kidney, the RVR was increased in both experimental periods, achieving $47 \%$ increase after $60 \mathrm{~min}$ perfusion, in the HD group (Figure 1A). UF was augmented at $60 \mathrm{~min}(77 \%)$ (Table 2). The GFR showed a decrease (34\%) in the HD group at 60 min (Figure 1). Furthermore, the RPF decreased in both times, and the PP increased at $60 \mathrm{~min}$, in HD. However, the tubular ion transport of $\mathrm{Na}+, \mathrm{Cl}-, \mathrm{K}+$ have not changed in the HD (Table 2).

\section{Histological Analysis}

The morphometric measurements evaluated demonstrate that the glomeruli were retracted in the HD kidneys as shown by the reduction of the BCA (30\%), GTA (27\%), and BSA (49\%) (Figure 2).

The kidney lipid deposition showed a 3-fold increase in HD compared to ND (ND: $1.5 \pm 0.17 \%$ /area; HD: $5.9 \pm 0.06 \% /$ area) (Figure 3).

\section{Inflammatory Markers}

IL-6, a pro-inflammatory cytokine, was significantly increased in HD (ND: $1,276 \pm 203$; HD: $1,982 \pm 47 \mathrm{pg} / \mathrm{mg}$ of protein). In addition, IL1b was also increased (ND: $97 \pm 12$ HD: $133 \pm 5$

TABLE 2 | Renal functional parameters of Perfusion Pressure, Renal Plasmatic Flow, and tubular transport of Sodium, Potassium, and Chloride at the end of the protocol of 8 weeks of isolated perfused kidney method.

$\begin{aligned} & \text { Isolated perfused } \\ & \text { kidney } \\ & \text { parameters }\end{aligned}$

\begin{tabular}{lccccc}
\hline & \multicolumn{2}{c}{30 min } & & \multicolumn{2}{c}{$6 \mathbf{~ m i n}$} \\
\cline { 2 - 3 } \cline { 5 - 6 } PP & $114.7 \pm 3.9$ & $130.0 \pm 6.7$ & & $112 \pm 3.5$ & $130 \pm 7^{\star}$ \\
RPF & $26 \pm 2.1$ & $19.2 \pm 1.3^{*}$ & & $26 \pm 2$ & $20 \pm 1.4^{*}$ \\
UF & $0.14 \pm 0.014$ & $0.15 \pm 0.03$ & & $0.14 \pm 0.01$ & $0.23 \pm 0.04^{*}$ \\
\%T Na & $83.6 \pm 0.9$ & $83.7 \pm 3.2$ & & $80 \pm 3$ & $72 \pm 5$ \\
\%T K & $61.3 \pm 5.3$ & $69.0 \pm 5.6$ & & $61 \pm 5$ & $65 \pm 3$ \\
\%T Cl & $89.9 \pm 3.7$ & $79.8 \pm 4.0$ & & $81 \pm 3$ & $76 \pm 4$ \\
\hline
\end{tabular}

Perfusion Pressure (PP, mmHg), RPF (Renal Plasmatic Flow, $m L \cdot g^{-1} \cdot m^{-1}{ }^{-1}$ ), UF (Urinary Flow, $\left.\mathrm{mL} \cdot \mathrm{g}^{-1} \cdot \mathrm{min}^{-1}\right)$, Percentage of Sodium tubular transport $\left(\% \mathrm{~T} \mathrm{Na}{ }^{+}\right)$, Percentage of Potassium tubular transport $\left(\% T \mathrm{~K}^{+}\right.$) and Percentage of Chloride Tubular transport (\%T $\left.\mathrm{Cl}^{-}\right)$. ND, Normal Diet; HD, High-Fat Diet. ${ }^{*} p \leq 0.05$ vs. ND. $\mathrm{pg} / \mathrm{mg}$ of protein), with no remarkable changes in the TNF- $\alpha$ and IL-10 levels (Figure 4).

\section{Correlations Analysis}

We observed a strong negative correlation between intra-renal lipid content and GFR $(R=-0.84, p=0.0097)$. Furthermore, there was a positive correlation between intrarenal lipid content and IL-6 $(R=0.79 . p=0.02)$.

\section{DISCUSSION}

In the present study, we investigated the morphological and functional kidney responses in adult rats, exposed to a high-fat diet after weaning. Our findings provide evidence that the consumption of this diet during this critical developmental period induces renal lipid accumulation, increases pro-inflammatory cytokines content and loss of renal function.

After 8 weeks of high-fat diet, the HD group presented no difference in weight gain, and a reduction in food but not at caloric consumption compared to the ND group. These data corroborate our previous demonstration that rats fed a highfat diet consume less food and have no increase in body weight gain, but have significantly higher adiposity (11). In addition, this animal model of metabolic syndrome is characterized by increased leptin and triglycerides levels, but lower adiponectin and normal insulin levels (11). In this context, we decided to investigate the potential renal complications associated with the current model.

We observed that HD animals did not increase the fasting blood glucose, but presented an increase in AUC and a decreased Kitt. These results demonstrate that these animals developed glucose intolerance and insulin resistance. These results were similar to those of who demonstrated the same response in mice fed a cafeteria diet (32).

The high-fat diet intake induced in vivo changes in renal function, as observed by the decrease in GFR and serum creatinine accumulation $(33,34)$. Moreover, in the isolated perfused kidney we also observed a decrease in GFR. Interestingly, the animals fed a high-fat diet had an increased intra-renal lipid content. Our study corroborates Muller et al. (20) which observed a higher kidney lipid content in mice fed a cafeteria diet. Similarly, Bobulescu et al. (27) showed in humans, a direct association between body mass index and kidney lipid deposition. Kidney lipid accumulation has been associated with renal function injury and can be a risk factor in CKD (19). However, little is known about how this pathogenic process occurs in the kidneys, especially when compared to the knowledge base regarding the deleterious effects of lipids on other organs such as the heart, liver, and skeletal muscle (35).

The intrarenal lipid accumulation is correlated to the GFR reduction in the $\mathrm{HD}$ group and can be the cause of morphological alteration in the glomeruli observed by a decrease in the Bowman's capsule, Bowman's space and GTAs demonstrating a glomeruli retraction. In a previous study from our group, Muller and coworkers showed that mice fed a cafeteria diet presented similar morphological kidney damage (20). These glomeruli 
A

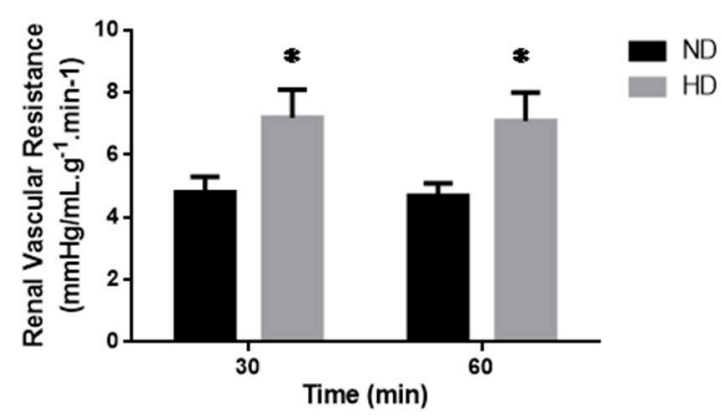

B

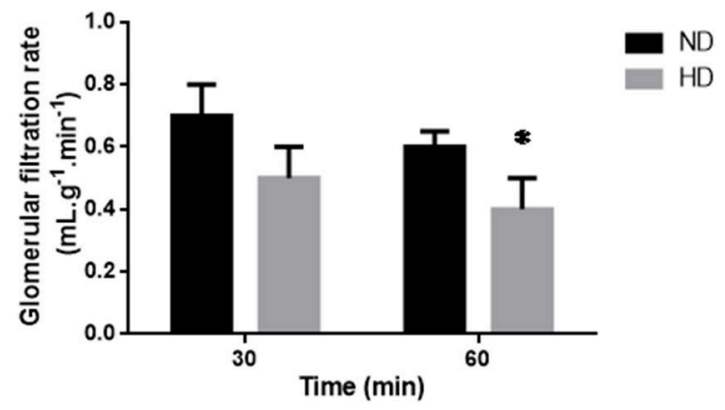

FIGURE 1 | Isolated perfused kidney. Renal Vascular Resistance (A; RVR), and Glomerular Filtration Rate (B; GFR) of isolated perfused kidneys from ND, Normal Diet; HD, High-Fat Diet. The results are expressed as mean \pm SEM * $p \leq 0.05$ vs. ND.

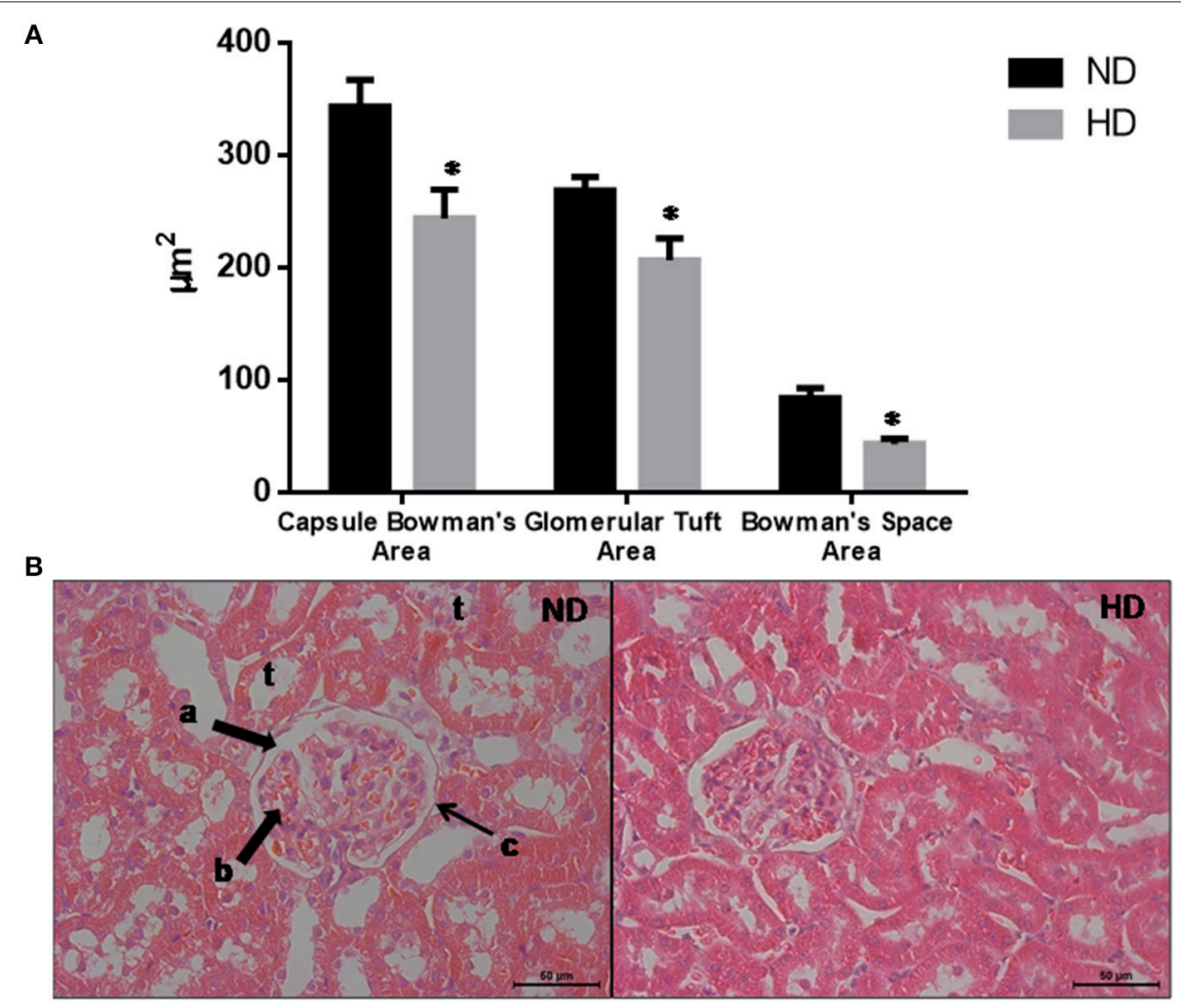

FIGURE 2 | Glomerular morphological parameters. (A) Morphologic parameters of renal histology. (B) Representative glomeruli. Lowercase letters show: a. Bowman's Space; b. glomerular tuft; c. Bowman's capsule; t: tubules. Magnification: X400. ND, Normal Diet; HD, High-Fat Diet. * $0 \leq 0.05$ vs. ND.

retraction could be at least in part induced by mesangial cell contraction (MCC). It was demonstrated that MCC could be induced by release of vasoactive hormones such as angiotensin II, that decrease the capillary surface area and consequently reducing the GFR (36-40).

To support this idea, recently our group showed in isolated perfused kidneys obtained from rats under high fructose diet, another experimental metabolic syndrome model, a progressive fall in the GFR associated by an increase in the renal concentrations of angiotensin I and angiotensin II (41). Moreover, unpublished data from our laboratory showed that angiotensin II blockade by losartan in the isolated perfused kidney method determine a higher RVR decrease more in the HD group than the ND group suggesting that the angiotensin II has an important contribution to the RVR rise in the HD.

In the present study, the isolated perfused kidney also demonstrated that in HD group there is an increase in RVR with no changes in tubular sodium and potassium transport 


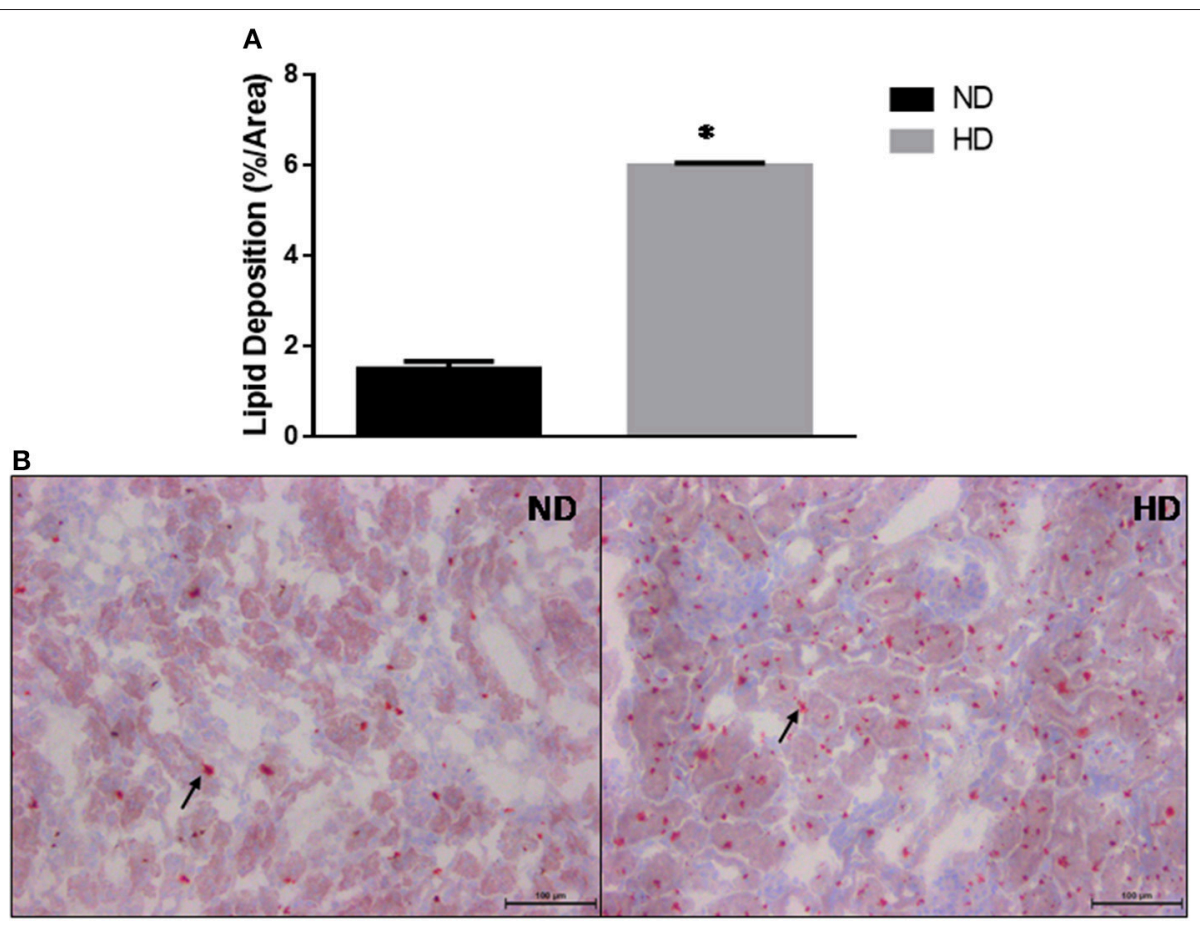

FIGURE 3 | Kidney lipid deposition. (A) Estimated percentage of lipids in the kidney. (B) Lipid deposition in ND and HD, arrows show lipids droplets. Magnification 200X. ND, Normal Diet; HD, High-Fat Diet. ${ }^{*} p \leq 0.05$ vs. ND.
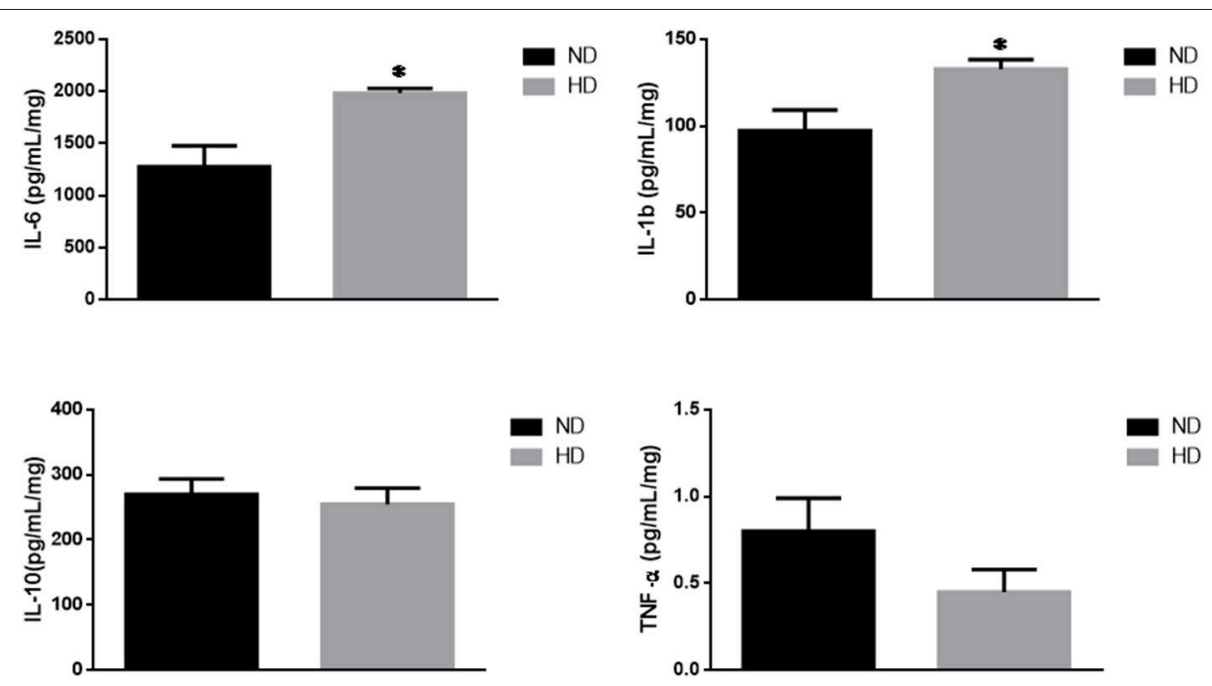

FIGURE 4 | Inflammatory cytokines. Effects of high-fat diet on cytokines (pg/mg of protein): (A) Interleukin 6 (IL-6), (B) Interleukin 1b (IL-1b), (C) Interleukin 10 (IL-10), and (D) Tumor Necrosis Factor-alpha (TNF- $\alpha$ ). ND, Normal Diet; HD, High-Fat Diet. ${ }^{*} p \leq 0.05$ vs. ND.

suggesting that changes in renal function are associated with glomerular alterations.

We have also shown that the inflammatory markers were changed by the high-fat diet consumption, as observed by the increase in the kidney pro-inflammatory cytokines IL-6 and IL-1b. Interestingly there was no change in the amount of the anti-inflammatory cytokine IL-10. Considering that we did not measure macrophages infiltration in the kidney, we cannot affirm if the source of cytokine production is local or from other tissues, such as adipose tissue. Despite this limitation, it is important to consider that the increased concentration of pro-inflammatory cytokines in the kidney reveals that this tissue is exposed to the deleterious effects typically generated by chronic inflammation, and therefore, may increase the risk of 
development of lipotoxicity and CKD. Additionally, we observed a positive correlation between kidney lipid accumulation and the IL- 6 content in this organ. Saja et al. (42) have demonstrated that animals with dyslipidemia developed inflammation that played a key role in mediating the deleterious changes in kidney function. Previous experiments have also shown a strong association between renal lipid accumulation and increased renal pro-inflammatory mediators, such as interleukin-1 (IL-1), interleukin-6 (IL-6), and TNF $\alpha$ (19). The renal lipotoxicity is also strongly associated with the development of proteinuria, glomerulonephritis and CKD (27). Moreover, Chung et al. (43) have demonstrated that hypertensive animals fed a high-fat diet have increased the angiotensin II, which is associated with kidney lipid deposition, lipotoxicity, and inflammation (43). In this context, our results suggest that the loss of renal function in the HD group can be caused by a lipotoxicity process however more experiments are necessary for the future to support this idea.

\section{CONCLUSION}

Our study provides evidence that high-fat diet consumption leads to renal lipid accumulation, increases inflammatory cytokines, induces glomeruli retraction, and renal dysfunction. These damages observed in the kidney could be associated with an increased risk to advanced CKD in adulthood suggesting that

\section{REFERENCES}

1. de Castro Engler R, Guimarães LH, Lacerda ACG. Design e consumo: a influência da mídia sobre a obesidade infantil. Blucher Design Proc. (2016) 2:5625-37. doi: 10.5151/despro-ped2016-0529

2. WHO. Noncommunicable Diseases: Progress Monitor. World Health Organization (2017).

3. Aranceta J, Pérez-Rodrigo C. Recommended dietary reference intakes, nutritional goals and dietary guidelines for fat and fatty acids: a systematic review. Br J Nutr. (2012) 107(Suppl 2):S8-22. doi: 10.1017/S0007114512001444

4. Elmadfa I, Kornsteiner M. Dietary fat intake-a global perspective. Ann Nutr Metab. (2009) 54(Suppl 1):8-14. doi: 10.1159/000220822

5. Coelho DF, Pereira-Lancha LO, Chaves DS, Diwan D, Ferraz R, CamposFerraz PL, et al. Effect of high-fat diets on body composition, lipid metabolism and insulin sensitivity, and the role of exercise on these parameters. Braz J Med Biol Res. (2011) 44:966-72. doi: 10.1590/S0100-879X2011007500107

6. Mensink RP. Effects of Saturated Fatty Acids on Serum Lipids and Lipoproteins: A Systematic Review and Regression Analysis. World Health Organization (2016).

7. WHO. NCDs, T. Best Buys' and Other Recommended Interventions for the Prevention and Control of Noncommunicable Diseases. World Health Organization (2017).

8. Mallarino C, Gómez LF, González-Zapata L, Cadena Y, Parra DC. Advertising of ultra-processed foods and beverages: children as a vulnerable population. Rev Saude Public. (2013) 47:1006-10. doi: 10.1590/S0034-8910.2013047004319

9. Lobstein T, Jackson-Leach R, Moodie ML, Hall KD, Gortmaker SL, Swinburn BA, et al. Child and adolescent obesity: part of a bigger picture. Lancet. (2015) 385:2510-20. doi: 10.1016/S0140-6736(14)61746-3

10. Reynolds CM, Gray C, Li M, Segovia SA, Vickers MH. Early life nutrition and energy balance disorders in offspring in later life. Nutrients. (2015) 7:8090-111. doi: 10.3390/nu7095384 reduction of high-fat ingestion during an early period of life can prevent metabolic disturbances and renal lipotoxicity.

\section{ETHICS STATEMENT}

This study was carried out in accordance with the recommendations of Guide for the Care and Use of Laboratory Animals published by the US National Institutes of Health ( $\mathrm{n}$. 85-23, revised in 1996) and approved by the Ethics Committee of Mackenzie Presbyterian University (Protocol: 063/02/2010).

\section{AUTHOR CONTRIBUTIONS}

CM participated in research design, writing of the paper, performance of the research, and data analysis. AL and RP participated in the performance of research, data analysis and writing of the paper. RY and AA participated in the performance of research and data analysis. NN participated in the performance of research. FE, VF, PF, and MF participated in the performance of research and writing of the paper.

\section{ACKNOWLEDGMENTS}

This study was supported by grants from MackPesquisa (number 059/11) to PF. AA and CM held a scholarship from Mackenzie PIBIC.
11. Fiorino P, Américo ALV, Muller CR, Evangelista FS, Santos F, Leite APO, et al. Exposure to high-fat diet since post-weaning induces cardiometabolic damage in adult rats. Life Sci. (2016) 160:12-7. doi: 10.1016/j.lfs.2016. 07.001

12. Te Morenga L, Montez JM. Health effects of saturated and trans-fatty acid intake in children and adolescents: systematic review and metaanalysis. PLoS ONE. (2017) 12:e0186672. doi: 10.1371/journal.pone.01 86672

13. Oosterman JE, Foppen E, van der Spek R, Fliers E, Kalsbeek A, la Fleur SE. Timing of fat and liquid sugar intake alters substrate oxidation and food efficiency in male Wistar rats. Chronobiol Int. (2015) 32:289-98. doi: 10.3109/07420528.2014.971177

14. Guebre-Egziabher F, Alix PM, Koppe L, Pelletier CC, Kalbacher E, Fouque D, et al. Ectopic lipid accumulation: a potential cause for metabolic disturbances and a contributor to the alteration of kidney function. Biochimie. (2013) 95:1971-9. doi: 10.1016/j.biochi.2013.07.017

15. Landeiro FM, Quarantini LdC. Obesidade: controle neural e hormonal do comportamento alimentar. Revista de Ciências Médicas e Biológ. (2011) 10:236-45. doi: 10.9771/cmbio.v10i3.5883

16. Jiang T, Wang Z, Proctor G, Moskowitz S, Liebman SE, Rogers T, et al. Diet-induced obesity in $\mathrm{C} 57 \mathrm{BL} / 6 \mathrm{~J}$ mice causes increased renal lipid accumulation and glomerulosclerosis via a sterol regulatory elementbinding protein-1c-dependent pathway. J Biol Chem. (2005) 280:32317-25. doi: 10.1074/jbc.M500801200

17. Kume S, Uzu T, Araki S, Sugimoto T, Isshiki K, Chin-Kanasaki M, et al. Role of altered renal lipid metabolism in the development of renal injury induced by a high-fat diet. J Am Soc Nephrol. (2007) 18:2715-23. doi: 10.1681/ASN.2007010089

18. Escasany E, Izquierdo-Lahuerta A, Medina-Gomez G. Underlying mechanisms of renal lipotoxicity in obesity. Nephron. (2019). doi: 10.1159/000494694. [Epub ahead of print].

19. Martins AR, Mas S. Lipotoxicity and kidney. Portug J Nephrol Hypertens. (2015) 29:306-15. doi: 10.32932/pjnh 
20. Muller CR, Américo ALV, Fiorino P, Evangelista FS. Aerobic exercise training prevents kidney lipid deposition in mice fed a cafeteria diet. Life Sci. (2018) 211:140-6. doi: 10.1016/j.lfs.2018.09.017

21. Wahba IM, Mak RH. Obesity and obesity-initiated metabolic syndrome: mechanistic links to chronic kidney disease. Clin J Am Soc Nephrol. (2007) 2:550-62. doi: 10.2215/CJN.04071206

22. Nosadini R, Tonolo G. Role of oxidized low density lipoproteins and free fatty acids in the pathogenesis of glomerulopathy and tubulointerstitial lesions in type 2 diabetes. Nutr Metab Cardiovasc Dis. (2011) 21:79-85. doi: 10.1016/j.numecd.2010.10.002

23. Takabatake Y, Yamamoto T, Isaka Y. Stagnation of autophagy: a novel mechanism of renal lipotoxicity. Autophagy. (2017) 13:775-6. doi: 10.1080/15548627.2017.1283084

24. Abrass CK. Cellular lipid metabolism and the role of lipids in progressive renal disease. Am J Nephrol. (2004) 24:46-53. doi: 10.1159/0000 75925

25. Keane WF. The role of lipids in renal disease: Future challenges. Kidney Int. (2000) 57:S27-31. doi: 10.1046/j.1523-1755.57.s75.3.x

26. Zhou Y, Lin S, Zhang L, Li Y. Resveratrol prevents renal lipotoxicity in high-fat diet-treated mouse model through regulating PPAR- $\alpha$ pathway. Mol Cell Biochem. (2016) 411:143-50. doi: 10.1007/s11010-0152576-y

27. Bobulescu IA. Renal lipid metabolism and lipotoxicity. Curr Opin Nephrol Hypertens. (2010) 19:393-402. doi: 10.1097/MNH.0b013e32833aa4ac

28. Bonora E, Moghetti P, Zancanaro C, Cigolini M, Querena M, Cacciatori $\mathrm{V}$, et al. Estimates of in vivo insulin action in man: comparison of insulin tolerance tests with euglycemic and hyperglycemic glucose clamp studies. J Clin Endocrinol Metab. (1989) 68:374-8. doi: 10.1210/jcem68-2-374

29. Fonteles MC, Cohen JJ, Black AJ, Wertheim SJ. Support of kidney function by long-chain fatty acids derived from renal tissue. Am J Physiol. (1983) 244:F235-246. doi: 10.1152/ajprenal.1983.244.3.F235

30. Bowman RH, Maack T. Effect of albumin concentration and ADH on $\mathrm{H} 2 \mathrm{O}$ and electrolyte transport in perfused rat kidney. Am J Physiol. (1974) 226:42630. doi: 10.1152/ajplegacy.1974.226.2.426

31. Martinez-Maldonado M, Opava-Stitzer S. Free water clearance curves during saline, mannitol, glucose and urea diuresis in the rat. J Physiol. (1978) 280:48797. doi: 10.1113/jphysiol.1978.sp012396

32. Higa TS, Spinola AV, Fonseca-Alaniz MH, Evangelista FS. Comparison between cafeteria and high-fat diets in the induction of metabolic dysfunction in mice. Int J Physiol Pathophysiol Pharmacol. (2014) 6:47-54.

33. Gomez-Guerrero C, Hernandez-Vargas P, Lopez-Franco O, Egido GOM. Mesangial cells and glomerular inflammation: from the pathogenesis to novel therapeutic approaches. Curr Drug Targets Inflamm Allergy. (2005) 4:341-51. doi: $10.2174 / 1568010054022169$
34. Herrera GA, Turbat-Herrera EA, Teng J. Mesangial homeostasis and pathobiology: their role in health and disease. Exp Models Renal Dis. (2011) 169:6-22. doi: 10.1159/000314774

35. Tsuboi N, Okabayashi Y, Shimizu A, Yokoo T. The renal pathology of obesity. Kidney Int Rep. (2017) 2:251-60. doi: 10.1016/j.ekir.2017.01.007

36. Henderson RM, Barber RD. Ion channels in renal glomerular mesangial cells. J Membr Biol. (1998) 163:1-8. doi: 10.1007/s002329900364

37. L'Azou B, Medina J, Frieauff W, Cordier A, Cambar J, Wolf A. In vitro models to study mechanisms involved in cyclosporine a-mediated glomerular contraction. Arch Toxicol. (1999) 73:337-45. doi: 10.1007/s002040050627

38. Pfeilschifter J. Cross-talk between transmembrane signalling systems: a prerequisite for the delicate regulation of glomerular haemodynamics by mesangial cells. Eur J Clin Invest. (1989) 19:347-61. doi: 10.1111/j.1365-2362.1989.tb00241.x

39. Potier M, Wolf A, Cambar J. Comparative study of cyclosporin A, cyclosporin $\mathrm{G}$, and the novel cyclosporin derivative IMM 125 in isolated glomeruli and cultured rat mesangial cells: a morphometric analysis. Nephrol Dial Transplant. (1998) 13:1406-11. doi: 10.1093/ndt/13.6.1406

40. Rodriguez-Barbero A, L'Azou B, Cambar J, López-Novoa JM. Potential use of isolated glomeruli and cultured mesangial cells as in vitro models to assess nephrotoxicity. Cell Biol Toxicol. (2000) 16:145-53. doi: 10.1023/A:1007683320660

41. Yokota R, Ronchi FA, Fernandes FB, Jara ZP, Rosa RM, Leite AP, et al. Intra-renal angiotensin levels are increased in high-fructose fed rats in the extracorporeal renal perfusion model. Front Physiol. (2018) 9:1433. doi: $10.3389 /$ fphys.2018.01433

42. Saja MF, Cook HT, Ruseva MM, Szajna M, Pickering MC, Woollard KJ, et al. A triglyceride-rich lipoprotein environment exacerbates renal injury in the accelerated nephrotoxic nephritis model. Clin Exp Immunol. (2018) 192:337-47. doi: 10.1111/cei.13111

43. Chung S, Park CW, Shin SJ, Lim JH, Chung HW, Youn D-Y, et al. Tempol or candesartan prevents high-fat diet-induced hypertension and renal damage in spontaneously hypertensive rats. Nephrol Dial Transplant. (2010) 25:389-99. doi: $10.1093 / \mathrm{ndt} / \mathrm{gfp} 472$

Conflict of Interest Statement: The authors declare that the research was conducted in the absence of any commercial or financial relationships that could be construed as a potential conflict of interest.

Copyright (c) 2019 Muller, Leite, Yokota, Pereira, Americo, Nascimento, Evangelista, Farah, Fonteles and Fiorino. This is an open-access article distributed under the terms of the Creative Commons Attribution License (CC BY). The use, distribution or reproduction in other forums is permitted, provided the original author(s) and the copyright owner(s) are credited and that the original publication in this journal is cited, in accordance with accepted academic practice. No use, distribution or reproduction is permitted which does not comply with these terms. 